\title{
Recent Progress on the Development of Engineered Silica Particles Derived from Rice Husk
}

\author{
Jinyoung Chun ${ }^{1}\left(\mathbb{D}\right.$ and Jin Hyung Lee ${ }^{2, *(\mathbb{D})}$ \\ 1 Energy \& Environment Division, Korea Institute of Ceramic Engineering \& Technology (KICET), Jinju 52851, \\ Gyeongnam, Korea; jchun@kicet.re.kr \\ 2 Convergence R\&D Division, Korea Institute of Ceramic Engineering \& Technology (KICET), Cheongju 28160, \\ Chungbuk, Korea \\ * Correspondence: leejinh1@kicet.re.kr; Tel.: +82-43-913-1502
}

Received: 26 November 2020; Accepted: 17 December 2020; Published: 21 December 2020

check for updates

\begin{abstract}
The development of engineered silica particles by using low-cost renewable or waste resources is a key example of sustainability. Rice husks have emerged as a renewable resource for the production of engineered silica particles as well as bioenergy. This review presents a state-of-the-art process for the development of engineered silica particles from rice husks via a bottom-up process. The first part of this review focuses on the extraction of Si from rice husks through combustion and chemical reactions. The second part details the technologies for synthesizing engineered silica particles using silicate obtained from rice husks. These include technologies for the precipitation of silica particles, the control of morphological properties, and the synthesis of ordered porous silica particles. Finally, several issues that need to be resolved before this process can be commercialized are addressed for future research.
\end{abstract}

Keywords: rice husk; rice husk ash; silica; engineered particle; bottom-up process; silica extraction; valorization; agricultural byproduct; sustainable material; biomass; renewable material

\section{Introduction}

Global rice and paddy production in 2018 was approximately 996 million tons as reported by the Food and Agricultural Organization [1]. The countries with the largest volume of rice and paddy production are located in Asia (China, India, Indonesia, Bangladesh, Vietnam, and Thailand). Rice husk is a residue produced during the rice mill process and on average, accounts for $20 \%$ of the paddy produced. The rice husk output in 2018 was approximately 199 million tons. Many countries use rice husks as a renewable energy resource for power generation [2]. The heating value of the rice husk is $15 \mathrm{MJ} \mathrm{kg}^{-1}$, and there is an energy potential of $2985 \mathrm{PJ}$ available per year [3]. Currently, rice husks are burnt in simple incinerators for resident energy, industrial streams, and thermal power plants in most Asian countries. Several Asian countries such as India, China, and Thailand are operating gasification power plants using rice husks $[4,5]$. Gasification power plants using rice husks have power capacities ranging between 20 and $400 \mathrm{kWe}$; however, they are still in the demonstration stage [6]. One ton of rice husk generates $800 \mathrm{kWh}$ of electric power [7] and after generating electric power, approximately 0.195 tons of rice husk ash is produced as a byproduct. High ash content in rice husks causes operational problems and consequently renders their thermal conversion difficult and expensive. Therefore, the valorization of rice husk ash for value-added material applications is important for improving the economic return of the entire process. In addition, the extraction of inorganic compounds from rice husks before energy generation could be worthwhile to reduce the burden of the energy production process. 
Rice husk ash mainly contains amorphous silica $\left(\mathrm{SiO}_{2}\right)$ and other metallic impurities. Rice husk-derived silica has gained increasing interest as a renewable source. Engineered silica particles have recently been intensively studied for bio-applications [8-10], energy storage [11,12], bioremediation [13], and as construction materials [14-17]. By increasing the utilization of engineered silica particles, the synthesis of engineered silica from renewable resources is considered to enhance sustainability. The use of rice husk silica for synthesizing engineered silica particles has advantages not only in the economy but also in mitigating environmental issues [18].

However, there is lack of comprehensive articles on the recovery and synthesis of silica particles derived from rice husks. Therefore, this review presents the recent progress in the development of engineered silica particles derived from rice husks.

\section{Purified Silica Extraction from Rice Husk}

\subsection{Combustion to Remove Organic Contents}

The most widely used method for obtaining silica from rice husks is direct combustion, resulting in the production of rice husk ash, which contains $85-95 \%$ silica [19-21]. The direct combustion of rice husk can produce thermal energy and can be used to generate steam, which subsequently drives the blades of a turbine to produce electricity. However, the direct combustion of rice husks generates greenhouse gases and emits significant quantities of particulate matter [22,23]. The emissions from rice husk burning contain $\mathrm{CO}_{2}, \mathrm{CH}_{4}, \mathrm{CO}, \mathrm{NO}_{\mathrm{x}}, \mathrm{SO}_{2}, \mathrm{PM}_{2.5}$, and $\mathrm{PM}_{10}$ of black carbon. Hence, when using direct combustion, it is important to always use both a dust collector and a gas absorber. The emission of $\mathrm{CO}_{2}$ from rice husk combustion is "net zero" because the hull reduces $\mathrm{CO}_{2}$ in nature. It also replaces the use of a fossil fuel. Therefore, the use of rice husk to produce energy is encouraged only when it is installed with emission control devices.

The phase change of silica depends on the combustion temperature. The silica in rice husks is a non-crystalline phase. As the combustion temperature increases over $600{ }^{\circ} \mathrm{C}$, the phase transformation to tridymite and cristobalite starts [24]. However, the crystallization temperature varied depending on the chemical composition of rice husk ash [25]. It was also reported that pretreated rice husk remained amorphous up to $1000^{\circ} \mathrm{C}$. At higher combusting temperatures, the physical properties of silica also change. Zareihassangheshlaghi et al. compared the physical properties of rice husk ashes synthesized at 700 and $900{ }^{\circ} \mathrm{C}$ [26]. At a higher combustion temperature $\left(900{ }^{\circ} \mathrm{C}\right)$, fewer metal impurities were observed. This might be due to the formation of more volatile and less stable phases that can be easily released into the gas phase. At this temperature, alkaline earth metal oxides can be refractory. At higher temperatures, the size of ash particles increases. Furthermore, the mesopores and micropores in the ash diminish after combustion at $900^{\circ} \mathrm{C}$. In rice husk ash, alkali metal impurities, such as K, P, $\mathrm{Ca}$, and $\mathrm{Mg}$, incorporate and form sticky alkali silicate at high combustion temperatures. This causes ash melting and agglomeration, which increases the size of particles and diminishes the meso- and micro-pores [27].

Previous studies report that combustion conditions could define the characteristics of silica; however, changes in characteristics could be within a narrow range: the specific surface area $\left(11-39 \mathrm{~m}^{2} \mathrm{~g}^{-1}\right)$, purity (29.7-96.7 wt \%), and crystallinity (completely amorphous or partially crystalline) [25]. The characteristics of the shape, particle size, pore, and uniformity cannot be controlled by changing the combustion conditions. Therefore, chemical treatment should be followed to synthesize the engineered silica particles.

\subsection{Principle of Chemically Extracting Silica from Rice Husk}

The main components of rice husk-cellulose, hemicellulose, lignin and inorganics-can be separated by their thermo-chemical properties. Figure 1 shows the phase changes of rice husk components depending on $\mathrm{pH}$. Under acidic conditions, cellulose and hemicellulose are dissolved in the aqueous phase and can be separated from solid residues, mainly lignin and inorganics [28]. 
During the hydrolysis of polysaccharides, metallic impurities, such as $\mathrm{K}_{2} \mathrm{O}, \mathrm{P}_{2} \mathrm{O}_{5}, \mathrm{CaO}$, and $\mathrm{MgO}$, were discarded by the washing step. Alkaline hydrothermal conditions induce the cleavage of ester linkages in lignin, which dissolves the lignin. After alkaline hydrothermal treatment, lignin can be removed from the solid residue $[29,30]$. The alkaline thermal treatment also dissolves silica and partially dissolves xylan to the liquid phase. The solubility of amorphous silica rapidly increases above $\mathrm{pH} 9.14$ [31]. It can be again solidified by decreasing the $\mathrm{pH}$. During solidification, silica particles can be engineered to have specific properties fit for their intended purpose. Residual organic compounds in the silica can be thermally removed at temperatures over $575^{\circ} \mathrm{C}$.

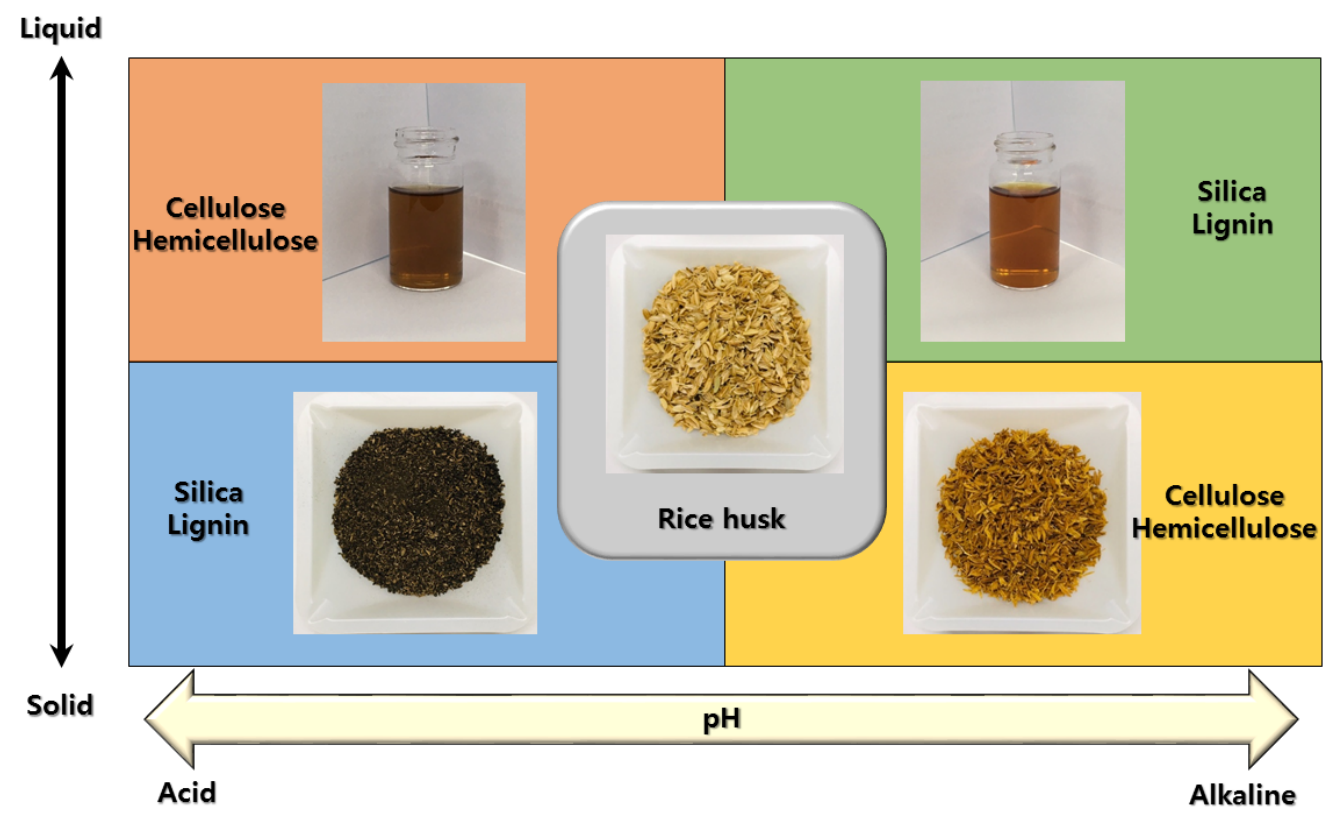

Figure 1. Phase change of rice husk components depending on $\mathrm{pH}$.

\subsection{Acid Leaching to Obtain High Purity Silica}

Acid leaching to remove organic matter and metallic impurities from rice husks was conducted before or after the combustion process. Acid leaching can produce a higher purity and specific surface area when compared to without acid leaching [19,32-34]. Lee et al. compared the performances of three acid solutions-sulfuric acid, hydrogen chloride, and oxalic acid-to remove the organic matter and metallic impurities [19]. Sulfuric acid effectively dissolved and removed both cellulose and hemicellulose but was not effective in removing lignin. Both hydrogen chloride and oxalic acid mainly reduced hemicellulose. The removal of metallic impurities was investigated depending on the acid solutions. However, the capability of acid solutions to remove organic and metallic impurities in rice husk varied depending on the solution's concentration, and the reaction time and temperature [35]. Traditionally, the acid leaching of rice husk was performed with sulfuric acid, hydrogen chloride [36], and nitric acid [33]. The use of a strong acid solution is significantly hazardous to the environment and human life. In addition, strong acid leaching produces not only soluble sugars but also smaller compounds such as aliphatic carboxylic acids and furans, which are inhibitors to microbes and enzymes. Therefore, attempts to replace these strong acid agents with environmentally harmless agents have been reported [19,37-40].

The environmentally harmless agents used to remove organic matter in rice husks were citric acid, ionic liquid, and deionized water. The use of citric acid could remove metallic impurities such as $\mathrm{Na}$, $\mathrm{K}, \mathrm{Ca}, \mathrm{Mg}$, $\mathrm{Fe}, \mathrm{Cu}$, etc., through a chelate reaction between carboxyl groups and metal elements $[37,38]$. Ionic liquids are green solvents and are effective in dissolving polysaccharides. The ionic liquids used to remove polysaccharides and metallic impurities from rice husks were 1-butyl-3-methylimidazolium chloride and 1-butyl-3-methylimidazolium hydrogen sulfate. The dissolved cellulose can be recovered 
by mixing with distilled water and further used to produce fermentable sugar [41]. Trinh et al. reported that ionic liquid-treated cellulose significantly changed its crystallinity, surface morphology, and composition, resulting in improved enzymatic digestibility. Conventionally, lignocellulose in rice husks is simply burned to generate energy, which leads to air pollution. However, the use of ionic liquid-treated cellulose to produce biofuel does not produce any pollutants. Therefore, using ionic liquids improves both the purity of silica and the comprehensive utilization of lignocellulose. Shen et al. used deionized water to leach metallic impurities, but water leaching was effective only on the external surface [40]. Mochidzuki et al. performed water leaching under pressurized conditions using a batch autoclave and steam explosion [42]. Both autoclave hot-water and steam-explosion-treated silica showed improved purities, even comparable to those obtained with the hydrochloric acid treatment. The pressurized water treatment dissolved some portion of the silica in hot water and changed its structure, which is more applicable to the synthesis of water-glass-like materials.

Most studies reported that acid leaching could improve the amorphousness of silica $[19,39,43]$. Alkali metals in rice husks facilitate the initiation of the formation of cristobalite, which causes the phase transformation of the silica [44]. Acid leaching could remove alkaline metals, which prevent the phase transformation of the silica. In addition, Real et al. reported that the leaching of rice husks with an acid solution before their combustion would yield silica powder with a high specific surface area [32]. However, if the acid leaching was performed after combustion, the specific surface area of silica would be poor.

\subsection{Alkali Extraction to Obtain Silicate}

Silica can be extracted from rice husk by solubilizing it in an alkali solution and precipitating in an acidic medium. In general, sodium hydroxide was used to extract silica from the rice husk as sodium silicate. The following formula represents the chemical reaction:

$$
\mathrm{SiO}_{2}(s)+2 \mathrm{NaOH}(l) \rightarrow \mathrm{Na}_{2} \mathrm{SiO}_{3}(l)+\mathrm{H}_{2} \mathrm{O}(l)
$$

Various hydrothermal conditions were used for the alkali extraction of silica. Most studies have prepared rice husk ash or acid-treated rice husk before the alkali extraction. Typically, thermal treatment is performed before alkali extraction to remove lignin. Otherwise, both lignin and silica were extracted from rice husks by alkali solution, which affected the quality of sodium silicate. In addition to the thermal treatment, organosolv fractionation can be applied to separate lignin by organic solvents such as ethanol [45] and 1,4-butanediol [46]. Rice husk ash was dissolved in sodium hydroxide solution at $80^{\circ} \mathrm{C}$ [47], $90^{\circ} \mathrm{C}$ [21,48], $100{ }^{\circ} \mathrm{C}$ [49], and even $150{ }^{\circ} \mathrm{C}$ [50]. In addition, a considerable amount of research has reported the performance of alkali extraction at room temperature [51-55]. In this case, rice husk ash was ground down to micron-sized particles and reacted for $24 \mathrm{~h}$. The concentrations of sodium hydroxide were varied in the range of 1-10 M, which determined the reaction time. Bazargan et al. showed the removal of lignin and silica from the rice husk, not rice husk ash, by the assistance of sodium hydroxide and hydrogen peroxide [56]. However, recoveries of silica and lignin in alkaline peroxide solution were only 75 and $60 \%$, respectively. Alkali extraction degrades lignin into phenolic compounds, such as benzoic acid, ferulic acid, and coniferyl aldehyde, and those cannot be utilized in further process.

\section{Synthesis of Engineered Silica Particles Using Silicate Extracted from Rice Husks}

As mentioned before, there is a limitation in changing the structure and shape of silica by changing the combustion conditions. Therefore, we focused on various methods for the synthesis of engineered silica particles using a sodium silicate solution extracted from rice husks. Such methods are based on a bottom-up process in which nano- or micron-sized particles are formed through chemical reactions of precursors at the atomic or molecular level. Although the overall synthetic procedure is relatively complex compared to methods based on a top-down process, the bottom-up process enables the precise 
and uniform control of the morphological properties of products. Accordingly, in modern industries that require biomass-derived silica, it is expected that research on the development of advanced synthetic techniques based on bottom-up processes will be more actively conducted in the future.

\subsection{Simple Precipitation of Silica Particles by the Addition of Acidic Reagents}

To obtain silica particles from a silicate solution, the $\mathrm{pH}$ of the solution should be adjusted to certain ranges to induce the precipitation of silica. Because the solubility of silica increases as the $\mathrm{pH}$ of the solution increases, the use of acidic reagents is the basic requirement for lowering the $\mathrm{pH}$ of an alkaline silicate solution [57]. The precipitation reaction of silica is simply described by the following equation, where $\mathrm{H}_{\mathrm{a}} \mathrm{X}$ is an acidic molecule:

$$
\mathrm{Na}_{2} \mathrm{SiO}_{3}+\mathrm{nH}_{\mathrm{a}} \mathrm{X} \rightarrow \mathrm{SiO}_{2}+\mathrm{nNa}_{\mathrm{a}} \mathrm{X}+\mathrm{H}_{2} \mathrm{O}
$$

Neutralization of sodium silicate solution using sulfuric acid is a common method for the precipitation of silica particles [58-63]. For example, in the paper reported by Ghorbani et al. [60], sodium silicate solution prepared from rice husk was titrated with diluted sulfuric acid to $\mathrm{pH} 7$ under vigorous stirring. The solution was further stirred for $24 \mathrm{~h}$ and then aged for $48 \mathrm{~h}$ at room temperature. After filtration and washing, the obtained silica gel was freeze-dried overnight. Amorphous silica particles prepared by this process exhibited an aggregated form of primary particles with an average size of $\sim 200 \mathrm{~nm}$, and the products showed a relatively high surface area of $409 \mathrm{~m}^{2} \mathrm{~g}^{-1}$. The agglomerated forms of silica particles were identically observed in other studies, where the silicate solution was titrated using sulfuric acid, although the sizes of the primary particles were different in each case [61-63]. The optimized process for the synthesis of pure silica nanoparticles reported by Nassar et al. was as follows [62]: (i) Dried rice husk was acid-leached by $2 \mathrm{M}$ nitric acid solution; (ii) After washing and drying, the dried residue was calcined at $600^{\circ} \mathrm{C}$; (iii) The obtained rice husk ash was refluxed with $2 \mathrm{M} \mathrm{NaOH}$ solution; (iv) The sodium silicate solution was separated by filtration; (v) The silicate solution was titrated with $1 \mathrm{M}$ sulfuric acid until the $\mathrm{pH}$ reached 7; (vi) The obtained silica gel was aged for $24 \mathrm{~h}$, and then calcined at $800{ }^{\circ} \mathrm{C}$. The final product prepared by this process exhibited peanut-like or irregularly shaped particles (Figure 2a,b). The TEM image shows irregular shaped particles composed of tiny nanoparticles that are 10-50 nm in size.Adam et al. reported the sol-gel synthesis of silica nanoparticles from rice husk using a template-free approach [64]. They simply titrated sodium silicate, which was obtained from rice husk, with nitric acid until the $\mathrm{pH}$ reached 9.0. After aging for 2 days, the yellowish gel was recovered by centrifugation and washed with distilled water. Because no template molecules were used, a further calcination step was not required. Through this process, amorphous silica nanoparticles assembled from primary particles of tens of nanometers were synthesized. Their surface area was $245 \mathrm{~m}^{2} \mathrm{~g}^{-1}$. Davarpanah et al. also used nitric acid for the titration of sodium silicate extracted from rice husk [65]. The $\mathrm{pH}$ of the solution was adjusted to 5.0, and the precipitated gel was aged for $24 \mathrm{~h}$. Figure $2 \mathrm{c}$ shows that the obtained silica was irregularly shaped nanoparticles composed of 10 to $20 \mathrm{~nm}$-sized primary particles. These morphological properties of precipitated silica particles have also been reported in previous studies using hydrochloric acid for $\mathrm{pH}$ adjustment [66-69].

The rise of environmental and safety issues has led to attempts to use organic acids instead of hazardous strong acids. In a study by Kalapathy et al., a silicate solution obtained from rice husk was titrated using citric acid or oxalic acid [70]. When the $\mathrm{pH}$ of the solution was adjusted to $4.0 \mathrm{or}$ 7.0, amorphous silica was successfully obtained. In contrast to the case of using hydrochloric acid, no impurity peaks were observed in the XRD measurements. Moreover, no significant difference in the silica yields were observed regardless of the type of acid. The experimental results reported by Liou et al. showed that the silica particles produced by oxalic acid or citric acid exhibited higher yields than the silica particles produced by hydrochloric acid or sulfuric acid [33]. However, the residual sodium content in the silica particles was relatively high when citric acid or oxalic acid was used for 
the precipitation reaction. The surface areas and pore volumes of silica produced by citric acid or oxalic acid were also lower than those of silica produced by hydrochloric acid (Figure 3).
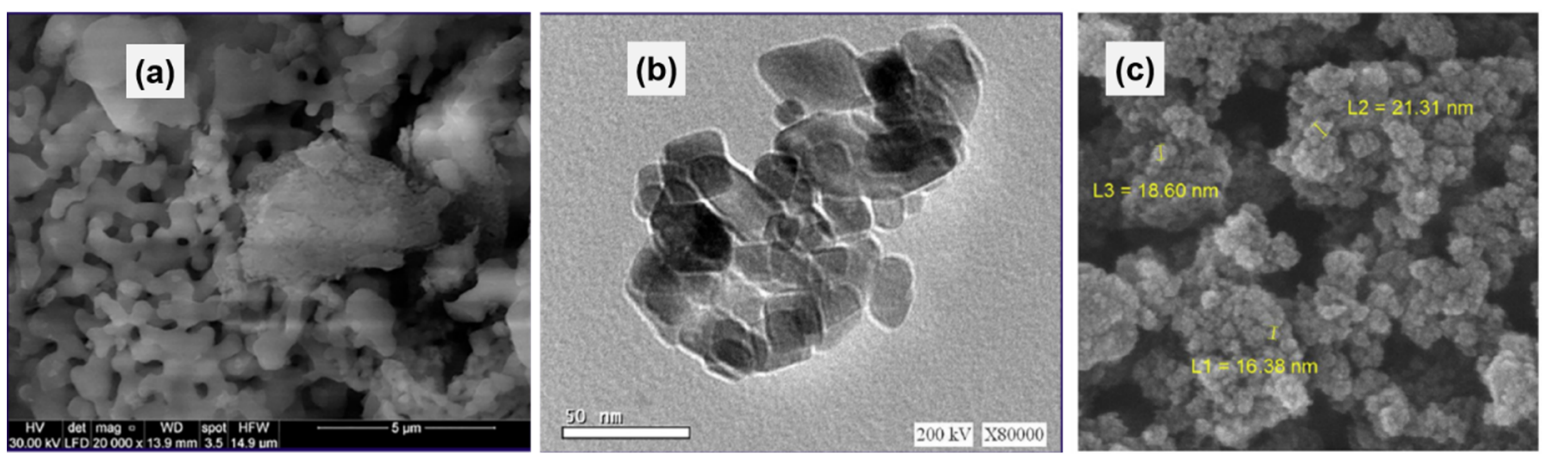

Figure 2. (a) SEM and (b) TEM images of silica nanoparticles prepared under the optimum condition reported by Nassar et al. (reprinted with permission from [62], Copyright 2019, Elsevier); and (c) SEM image of silica particles prepared by the titration of sodium silicate solution with nitric acid (reprinted with permission from [65], Copyright 2019, Elsevier).
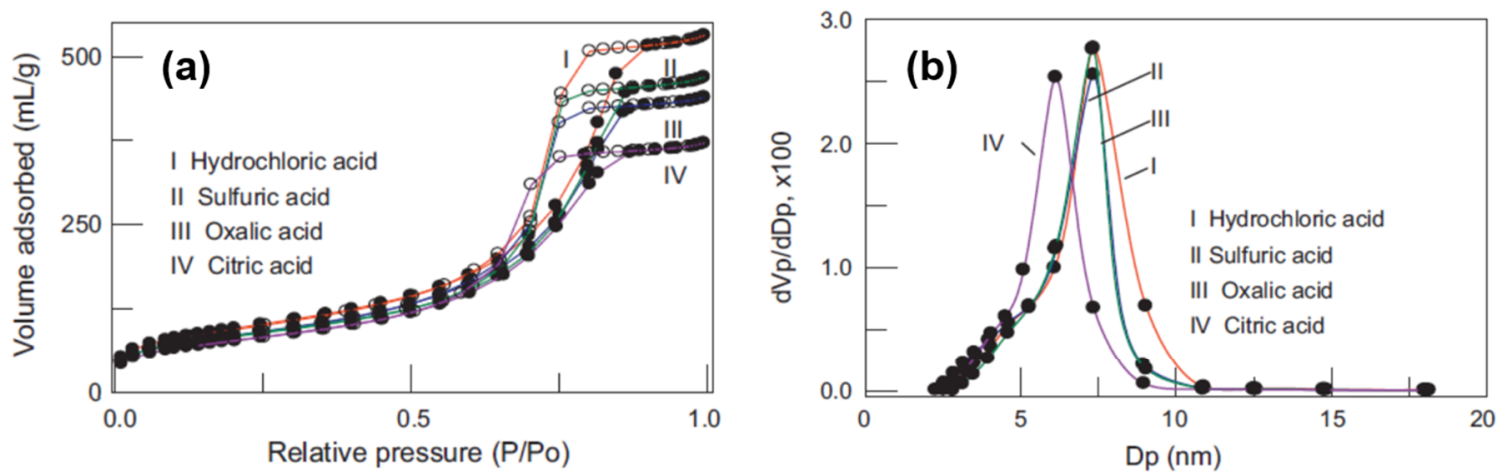

\begin{tabular}{|c|c|c|c|c|c|c|}
\hline & $\operatorname{SBET}\left(\mathrm{m}^{2} / \mathrm{g}\right)$ & $V_{\mathrm{t}}\left(\mathrm{cm}^{3} / \mathrm{g}\right)$ & $V_{\text {mic }}\left(\mathrm{cm}^{3} / \mathrm{g}\right)$ & $V_{\text {meso }}\left(\mathrm{cm}^{3} / \mathrm{g}\right)$ & $V_{\text {meso }} / V_{t}(\%)$ & Yield (\%) \\
\hline Sulfuric acid & 319 & 0.717 & 0.009 & 0.708 & 98.74 & 89.33 \\
\hline Oxalic acid & 313 & 0.672 & 0.004 & 0.668 & 99.40 & 95.05 \\
\hline
\end{tabular}

列

Figure 3. (a) Adsorption-desorption isotherm; (b) differential pore size distribution; and (c) BET (Brunauer-Emmett-Teller) surface area, pore volume, and extraction yield of silica samples prepared through various acid treatments (reprinted with permission from [33], Copyright 2011, Elsevier).

\subsection{Control of Morphological Properties of Silica Particles}

Although the precipitation of silica by adding acidic reagents is a simple and convenient method, it cannot precisely control the morphological properties of silica. Most of the silica prepared by this approach exhibited irregularly shaped large particles assembled by small-sized primary particles. Therefore, advanced synthetic methods that can control the shape and surface properties of silica are required to apply rice husk-derived silica particles to modern industries. In this section, we review previous studies that used (i) organic co-solvents, (ii) polymer additives, and (iii) a water-in-oil emulsion system to control the morphology of silica particles.

Zulkifli et al. used ethanol as a co-solvent at the precipitation step of silicate [71]. In this study, sodium silicate solution extracted from rice husks was mixed with different amounts of ethanol. Then, the mixed solution was titrated with phosphoric acid. As a result, while irregular and highly aggregated particles were obtained without ethanol, dispersed spherical particles were synthesized with increasing amounts of ethanol. At the optimized condition (ratio of sodium silicate: $\mathrm{H}_{2} \mathrm{O}$ ethanol $=1: 1: 0.25$ at $\mathrm{pH} 7$ ), uniform silica nanoparticles with low aggregation were obtained, and their sizes 
ranged from 75 to $252 \mathrm{~nm}$. The silica powders exhibited a BET surface area of $\sim 364 \mathrm{~m}^{2} \mathrm{~g}^{-1}$. It was surmised that the formation of spherical particles originated from the formation of self-emulsion droplets consisting of silicate anions upon the addition of ethanol to an aqueous silicate solution [72]. A similar phenomenon was also observed in a study by Zulfiqar et al. [21]. The neutralization of the silicate solution with phosphoric acid in the presence of ethanol led to the formation of spherical silica particles. Furthermore, as the concentration of sodium silicate increased, the average size of silica particles precipitated at room temperature also increased continuously (Figure 4). Silica particles made from sodium silicate solution containing $0.7 \mathrm{wt} \%$ white rice husk (WRH) had a unimodal size distribution of $181 \pm 17 \mathrm{~nm}$. When the concentration of WRH in the sodium silicate solution increased to $5.6 \mathrm{wt} \%$, the silica particles exhibited a tri-modal size distribution $(352 \pm 77 \mathrm{~nm}, 1.8 \pm 0.3 \mu \mathrm{m}$, and $7.1 \pm 1.3 \mu \mathrm{m}$ ). On the other hand, when the precipitation reaction progressed at $65^{\circ} \mathrm{C}$, the particle sizes decreased as the concentration of silicate solution increased.
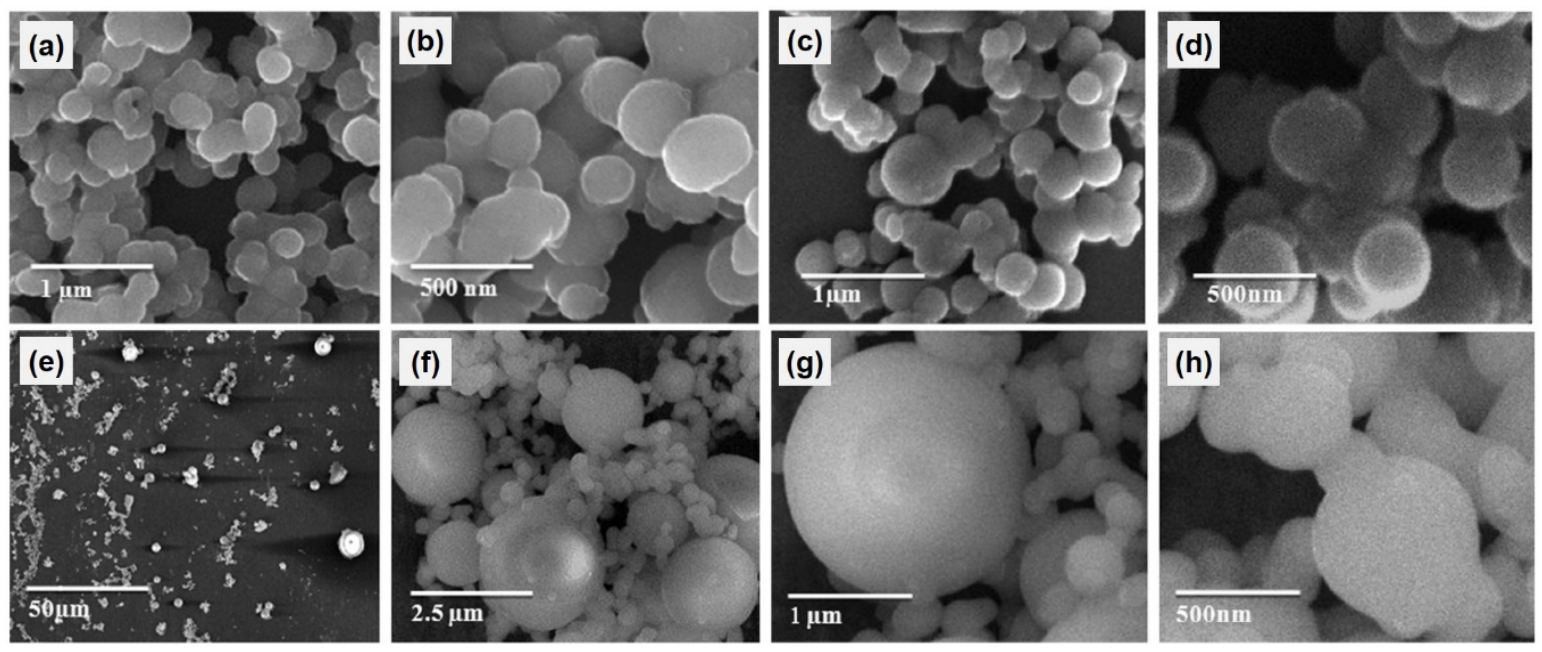

Figure 4. SEM images of silica particles produced at $25^{\circ} \mathrm{C}$ by using sodium silicate solution containing $(\mathbf{a}, \mathbf{b}) 1.4 \mathrm{wt} \%$, (c,d) $2.8 \mathrm{wt} \%$, and (e-h) $5.6 \mathrm{wt} \%$ white rice husk (WRH) (reprinted with permission from [21], Copyright 2015, Elsevier)

The use of acetone, an organic solvent, has also been shown to be effective in producing spherical silica particles. Rajan et al. [73] added $40 \mathrm{~mL}$ of acetone to $100 \mathrm{~mL}$ of sodium silicate solution extracted from rice husk. Afterwards, the $\mathrm{pH}$ of the solution was adjusted to 7 using $5 \mathrm{M}$ acetic acid. Through this optimized condition, they synthesized well defined spherical silica particles in the range of 200 to $400 \mathrm{~nm}$.

Several studies have reported the synthesis of spherical silica particles using a polymer additive. In particular, the spherical shape control was achieved when polymers with sufficient ethylene oxide (EO) chains were used as additives [74-77]. It is considered that the interaction of the EO chains of polymers with the silicate species stabilizes the silicate during the solidification process, which leads to the formation of spherical particles [78]. In a study by Li et al., [74,75], they first dissolved polyethylene glycol (PEG, molecular weight $=20,000$ ) in a sodium silicate solution. Then, by the titration of the silicate solution using phosphoric acid, spherical silica nanoparticles were obtained. Similar results were also reported by Le et al. [76]. When PEG (molecular weight $=10,000$ ) was used as an additive, spherical silica nanoparticles could be obtained from the rice husk-derived silicate solution. On the other hand, by using a Pluronic P-123 polymer instead of PEG, Shahnani et al. prepared silica microspheres from a rice husk-derived sodium silicate [77]. A certain amount of Pluronic P-123 was dissolved in $2 \mathrm{M}$ hydrochloric acid solution and then sodium silicate was added to the mixture. The overall reactions progressed under acidic conditions. After filtration and washing, the porous silica microspheres were obtained by calcination at $550{ }^{\circ} \mathrm{C}$. The non-aggregated silica microspheres obtained by this process are 
shown in Figure 5. The silica microspheres had a BET surface area of $445 \mathrm{~m}^{2} \mathrm{~g}^{-1}$ and a pore volume of $0.298 \mathrm{~cm}^{3} \mathrm{~g}^{-1}$, respectively.
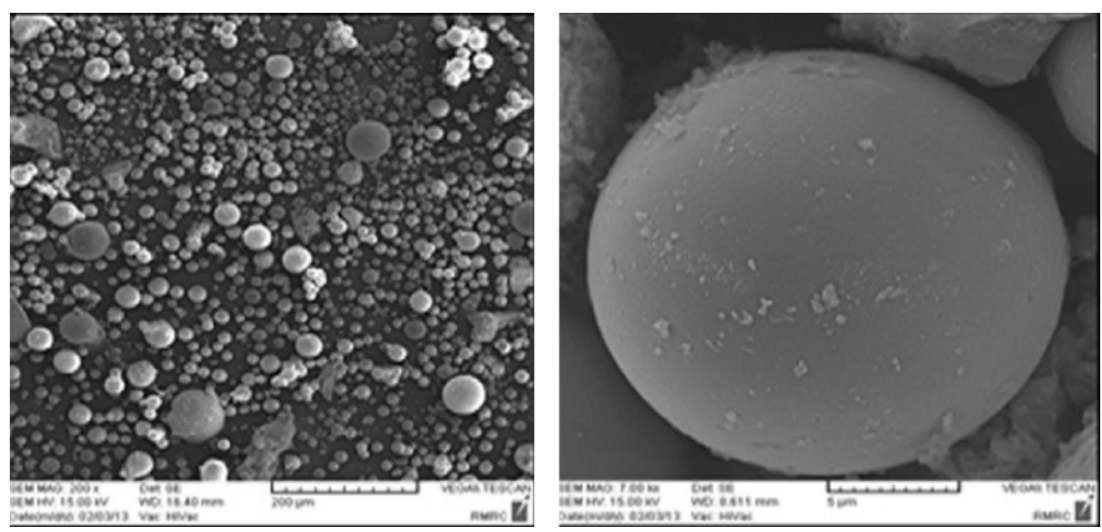

Figure 5. SEM images of the silica microspheres (reprinted with permission from [77], Copyright 2018, Elsevier).

The use of an emulsion system is a well known method for producing spherical particles. Hasan et al. reported a study that adapted this system for the preparation of spherical silica from a rice husk-derived silicate solution [79]. In the water-in-oil emulsion composed of water and toluene, cetyltrimethylammonium bromide (CTAB) and n-butanol were used as the surfactant and co-surfactant, respectively (Figure 6). After the formation of the reverse micelle, silicate was hydrolyzed by the urea at the micelle interface. The obtained silica particles exhibited a distinct spherical shape with a surface area and pore volume of $227 \mathrm{~m}^{2} \mathrm{~g}^{-1}$ and $1.24 \mathrm{~cm}^{3} \mathrm{~g}^{-1}$, respectively.

(a)
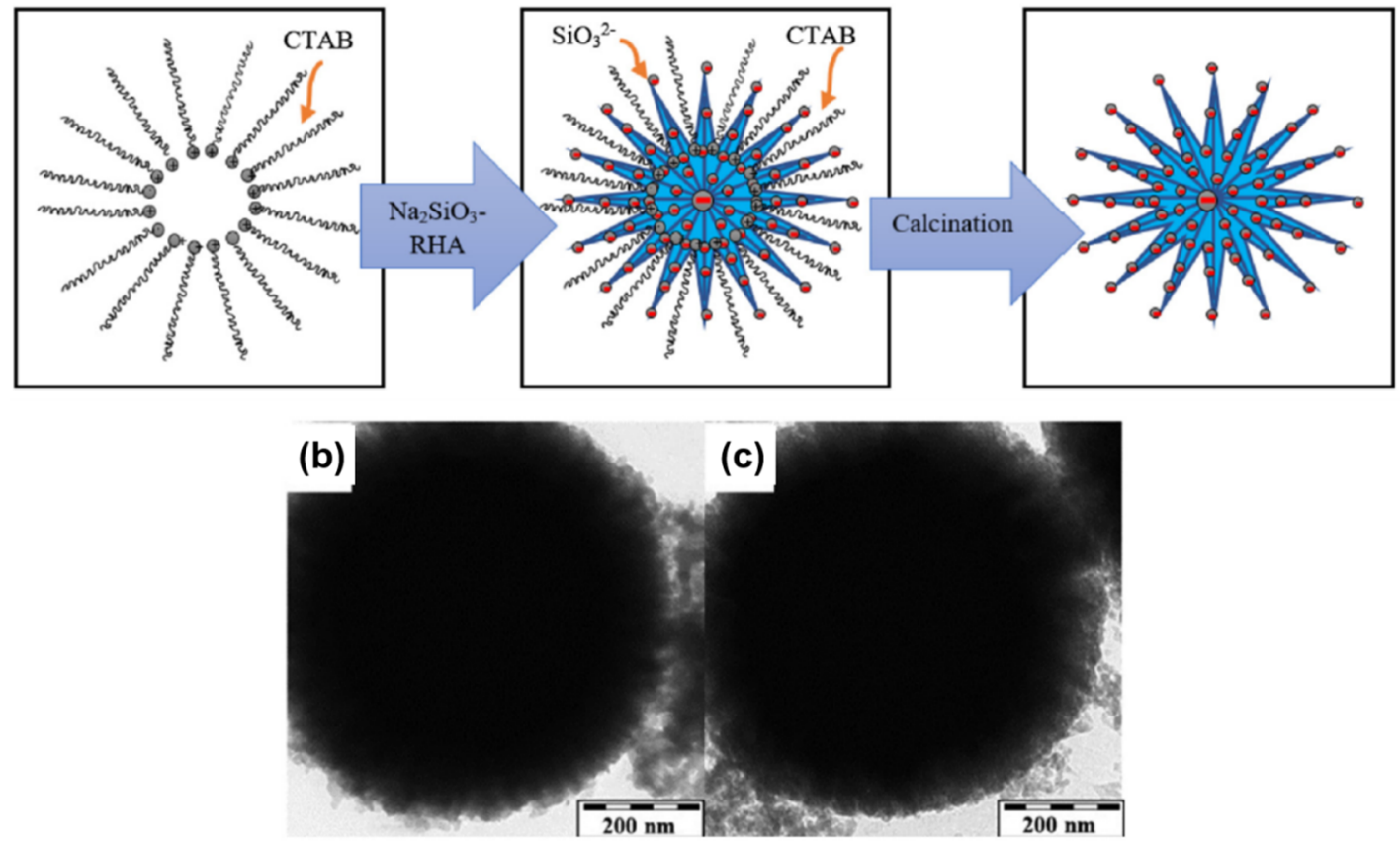

Figure 6. (a) Formation mechanism of silica sphere using $\mathrm{Na}_{2} \mathrm{SiO}_{3}-\mathrm{RHA}$ (rice husk ash) and CTAB (cetyltrimethylammonium bromide) in the water-in-oil emulsion system. TEM images of silica particles made from (b) commercial sodium silicate and (c) rice husk-derived sodium silicate (reprinted with permission from [79], Copyright 2018, Elsevier). 


\subsection{Synthesis of Ordered Porous Silica Particles from Rice Husk}

Since a mesoporous aluminosilicate using a soft-template synthetic method was developed by the Mobil Oil Corporation in 1992 [80], numerous studies have been conducted to synthesize various types of ordered porous materials. In the case of silica-based materials, starting with the MCM (Mobil Composition of Matter) series, research on the development of various types of mesoporous silica, such as SBA (Santa Barbara Amorphous), KIT (Korea Advanced Institute of Science and Technology), FDU (Fudan University), and MSU (Michigan State University) series, have been conducted. At the same time, the requirement for cost-effective processes has led to the search for low-cost silica precursors that can replace silicon alkoxide reagents. This is one of the main reasons why rice husk-derived silicate has attracted attention as a raw material for the synthesis of mesoporous silica.

In the last decade, MCM-type silica has been successfully produced from rice husks in many studies. Conventional MCM-41 silica has a uniform hexagonal pore structure with a pore size of 2-4 $\mathrm{nm}$. CTAB, a cationic surfactant, has been typically used as a structure-directing agent for MCM-41. $\mathrm{CTAB}$ forms rod-like micelles in the aqueous solution and aligns into a hexagonal array. The negatively charged silicate species above $\mathrm{pH} 10$ preferentially interact with the positively charged surfactant heads. Accordingly, after the removal of the surfactant by calcination, mesoporous silica with a hexagonal pore structure was obtained. An example of the synthetic method in detail with reference to the reported paper is as follows [81]. First, considering the specific molar composition of $\mathrm{SiO}_{2}, \mathrm{NaOH}, \mathrm{CTAB}$, and $\mathrm{H}_{2} \mathrm{O}$, a certain amount of CTAB was dissolved in distilled water. Then, this solution was added to the sodium silicate solution extracted from rice husk and stirred at $80^{\circ} \mathrm{C}$ for $24 \mathrm{~h}$. After the titration of the mixed solution using nitric acid to a $\mathrm{pH}$ of 10.0, it was aged for $48 \mathrm{~h}$ at the same temperature. The resulting gel was washed with distilled water and acetone, and subsequently calcined at $600{ }^{\circ} \mathrm{C}$. Through this process, Ramalingam et al. synthesized MCM-41 silica particles using rice husk as the silica precursor (Figure 7); it showed a hexagonal pore structure with a monomodal pore size of $2.3 \mathrm{~nm}$ and a high surface area of $1115 \mathrm{~m}^{2} \mathrm{~g}^{-1}$ [81].
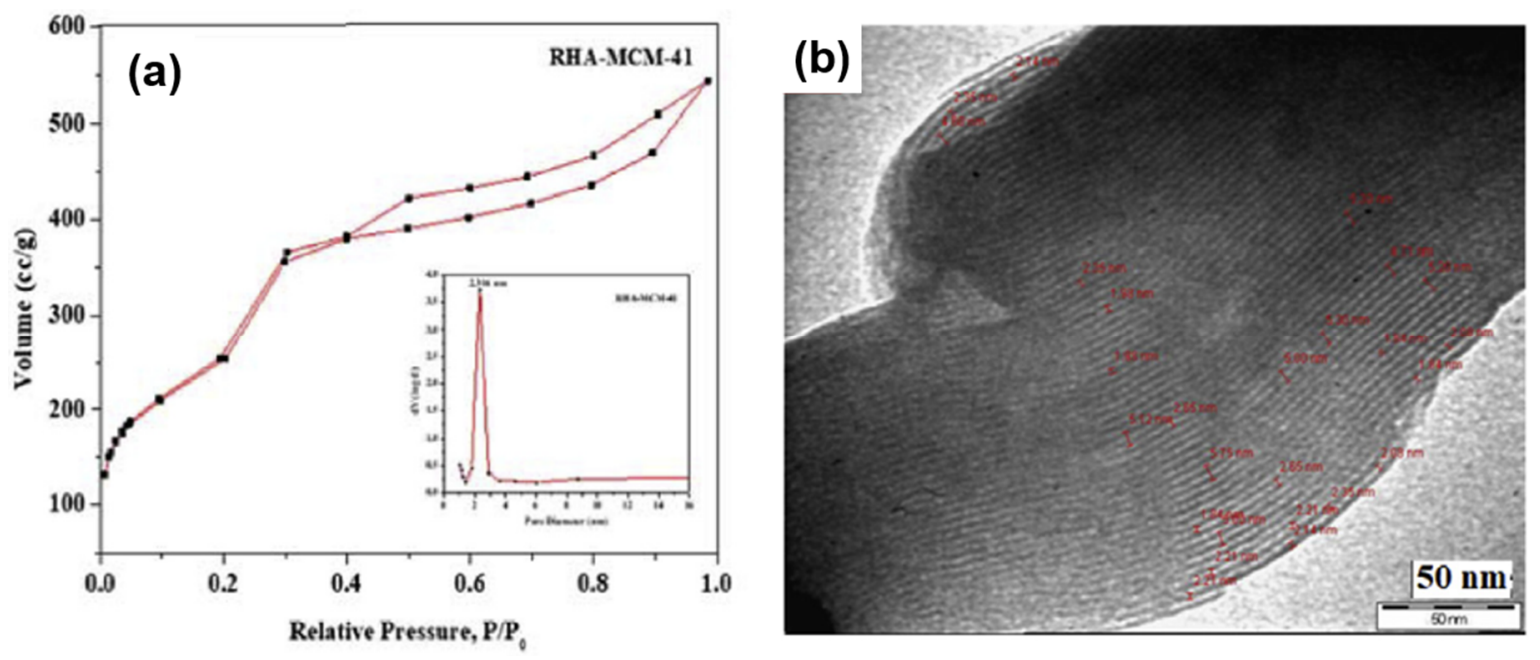

Figure 7. (a) $\mathrm{N}_{2}$ adsorption-desorption isotherm of rice husk ash-derived MCM (Mobile Composition of Matter)-41. The inset shows the corresponding pore size distribution; and (b) the TEM image of rice husk ash-derived MCM-41 (reprinted with permission from [81], Copyright 2020, Elsevier).

Unlike MCM-41 silica, MCM-48 silica has a three-dimensional pore structure with cubic $\mathrm{I}_{\mathrm{a} 3 \mathrm{~d}}$ symmetry. To obtain MCM-48 silica, the structure of the micelle formed by the self-assembly of surfactants must be changed. Several studies satisfied this condition by utilizing a cationic-neutral surfactant mixture system [82-84] or changing the surfactant concentration [85]. Subsequently, MCM-48 silica was successfully synthesized using sodium silicate solution extracted from rice husk. Looking at a specific example, Bhagiyalakshmi et al. used a mixture of CTAB and polyoxyethylene lauryl ether 
(LE-4) as the structure directing agents [83]. Sodium silicate solution was added to the surfactant mixture (CTAB and LE-4) dissolved in an aqueous solution at $80^{\circ} \mathrm{C}$. Then, the mixed solution was titrated using acetic acid until the $\mathrm{pH}$ reached 10, and heated at $100{ }^{\circ} \mathrm{C}$ for $48 \mathrm{~h}$. After filtration and washing, the final product was obtained by calcination at $550{ }^{\circ} \mathrm{C}$. The obtained MCM- 48 silica showed a bicontinuous $\mathrm{I}_{\mathrm{a} 3 \mathrm{~d}}$ cubic phase with a surface area of $1124 \mathrm{~m}^{2} \mathrm{~g}^{-1}$ and a main pore size of $3.9 \mathrm{~nm}$. Morphological properties, such as the surface area, pore volume, and main pore size of the rice husk-derived MCM-41 and MCM-48 silica reported to date are summarized in Table 1 [81-95].

Table 1. Pore diameter, surface area, and pore volume of MCM-type silica prepared from rice husk-derived silicate solution.

\begin{tabular}{|c|c|c|c|c|}
\hline Silica Type & Pore Diameter (nm) & Surface Area $\left(\mathrm{m}^{2} \mathrm{~g}^{-1}\right)$ & Pore Volume $\left(\mathrm{cm}^{3} \mathrm{~g}^{-1}\right)$ & Ref. \\
\hline \multirow{14}{*}{ MCM-41 } & 2.9 & 800 & 0.93 & [86] \\
\hline & 2.86 & 943 & - & [87] \\
\hline & 3.54 & 1101 & 0.96 & [83] \\
\hline & 3.51 & 1099 & 0.96 & [84] \\
\hline & 3.28 & 903 & - & [88] \\
\hline & 2.3 & 1115 & 0.92 & [89] \\
\hline & 3.6 & 602 & 0.49 & [90] \\
\hline & $2.8-3.1$ & $545-1210$ & $0.36-1.00$ & [85] \\
\hline & 2.92 & 797 & 0.57 & [91] \\
\hline & 3.16 & 1347 & 0.906 & [92] \\
\hline & 3.8 & 500.5 & 0.45 & [93] \\
\hline & $3.0-3.4$ & $552-769$ & $1.025-1.167$ & [94] \\
\hline & 2.71 & 972.5 & 0.87 & [95] \\
\hline & 2.3 & 1115 & 0.92 & [81] \\
\hline \multirow{4}{*}{ MCM-48 } & 4.02 & 1024 & 2.58 & [82] \\
\hline & 3.89 & 1124 & 0.98 & [83] \\
\hline & 2.6 & 1059 & 0.68 & [84] \\
\hline & 2.5 & 815 & 0.75 & [85] \\
\hline
\end{tabular}

SBA-15 is one of the most common types of mesoporous silica and was first developed at the University of California [96]. SBA-15 has a two-dimensional hexagonal pore structure. Its pore size can be controlled in the range of 4-12 nm. It can be further increased up to $30 \mathrm{~nm}$ by using additional organic additives. One important feature of SBA-15 is that it has thicker pore walls compared to MCM-41. Thus, SBA-15 is more stable under high temperature and hydrothermal conditions [97]. In order to obtain SBA-15 having these advantages from low-cost raw materials, a number of studies using silicate extracted from rice husk have been reported. For the synthesis of SBA-15, Pluronic P-123, a nonionic triblock copolymer, is used as a structure directing agent. SBA-15 is assembled by the $\mathrm{N}^{0} \mathrm{H}^{+} \mathrm{X}^{-} \mathrm{I}^{+}$mechanism, where $\mathrm{N}, \mathrm{H}, \mathrm{X}$, and I indicate nonionic surfactant, hydrogen, halide, and silica source, respectively. Therefore, in difference with a case of MCM-41, the synthetic reaction proceeds under acidic conditions. Under these synthetic conditions, Henao et al. obtained SBA-15, which had a monomodal pore size of $7.6 \mathrm{~nm}$ with a high surface area of $604 \mathrm{~m}^{2} \mathrm{~g}^{-1}$, from rice husk-derived silicate solution (Figure 8) [98]. Chareonpanich et al. synthesized SBA-15 from rice husk via an ultrasonic technique [99]; their SBA-15 exhibited a highly ordered hexagonal pore arrangement with a pore size of $9.5 \mathrm{~nm}$. In the meantime, by using the Pluronic F-127 polymer instead of P-123, SBA-16-type silica was also successfully obtained from rice husk [100]. The obtained SBA-16 showed a three-dimensional 
cubic pore structure with a pore size of $\sim 8.0 \mathrm{~nm}$. The morphological properties of rice husk-derived SBA-type silica reported in previous studies are summarized in Table $2[83,84,98-102]$.
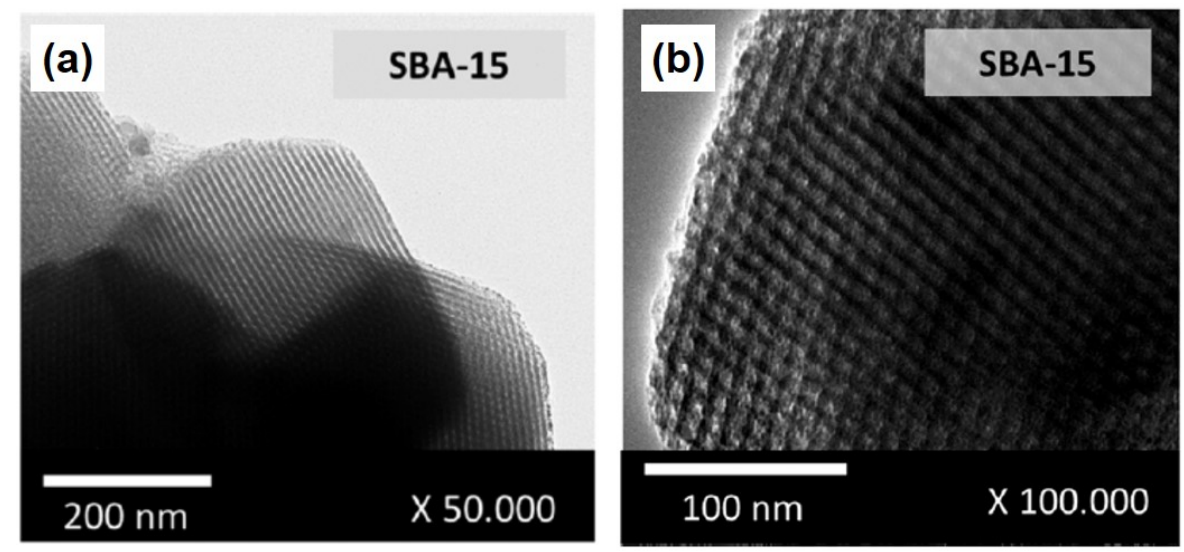

Figure 8. (a,b) TEM images of SBA (Santa Barbara Amorphous)-15-type mesoporous silica made from rice husk-derived silicate solution (reprinted with permission from [98], Copyright 2020, Elsevier).

Table 2. Pore diameter, surface area, and pore volume of SBA-type silica prepared from rice husk-derived silicate solution.

\begin{tabular}{|c|c|c|c|c|}
\hline Silica Type & Pore Diameter (nm) & Surface Area $\left(\mathrm{m}^{2} \mathrm{~g}^{-1}\right)$ & Pore Volume $\left(\mathrm{cm}^{3} \mathrm{~g}^{-1}\right)$ & Ref. \\
\hline SBA-11 & $3.8 / 7.7 / 12.9$ & 356 & 0.792 & [98] \\
\hline \multirow{6}{*}{ SBA-15 } & 9.5 & $530-860$ & $0.96-1.27$ & [99] \\
\hline & 4.8 & 790 & 0.82 & [101] \\
\hline & 5.8 & 712 & 0.68 & [83] \\
\hline & 7.4 & 780 & 0.95 & [84] \\
\hline & 7.7 & 1095 & 1.705 & [102] \\
\hline & 7.6 & 604 & 1.192 & [98] \\
\hline SBA-16 & $5.8-8.2$ & $775-840$ & - & [100] \\
\hline
\end{tabular}

The synthesis of large-pore-sized ordered mesoporous silica from rice husk was reported by Chun et al. [103]. In this study, Pluronic P-123 and trimethylbenzene (TMB) were used as templates and pore expanders, respectively. Pluronic P-123, TMB, and rice husk-derived silicate solution were assembled in a neutral environment with the addition of acetic acid. Through the $\mathrm{N}^{0} \mathrm{I}^{0}$ mechanism, amorphous silica with a well defined mesocellular foam structure was successfully obtained [104]. It has uniform mesopores with a size of approximately $30 \mathrm{~nm}$ and a large pore volume of $1.77 \mathrm{~cm}^{3} \mathrm{~g}^{-1}$ (Figure 9a-c). Interestingly, when the concentration of sodium silicate extracted from rice husk increased, the usage of acetic acid increased to adjust the neutral $\mathrm{pH}$, the pore size of silica was further expanded to approximately $60 \mathrm{~nm}$ (Figure $9 \mathrm{~d}-\mathrm{f}$ ). The authors suggested that the large amounts of acetate promote the oxolation reaction and increase the hydrophobicity of silica, which led to the further pore expansion of silica [103,105].

Although they are not pure silica materials, several types of zeolites have also been synthesized using silicate extracted from rice husks. Zeolites are microporous aluminosilicate materials. Therefore, additional alumina resources had to be used for zeolite synthesis. Using rice husk-derived silicate and sodium aluminate reagent as a raw silica and alumina material, respectively, the synthesis of zeolite A [106], zeolite Y in sodium form (NaY) [107,108], ZSM(Zeolite Socony Mobil)-5 [109], ZSM-12 [110], ZSM-48 [111], and Linde Type J zeolite [112] have been reported in previous studies. The synthesis of various kinds of zeolite from the rice husk-derived silicate solution is covered in detail in a previous review [113]. 

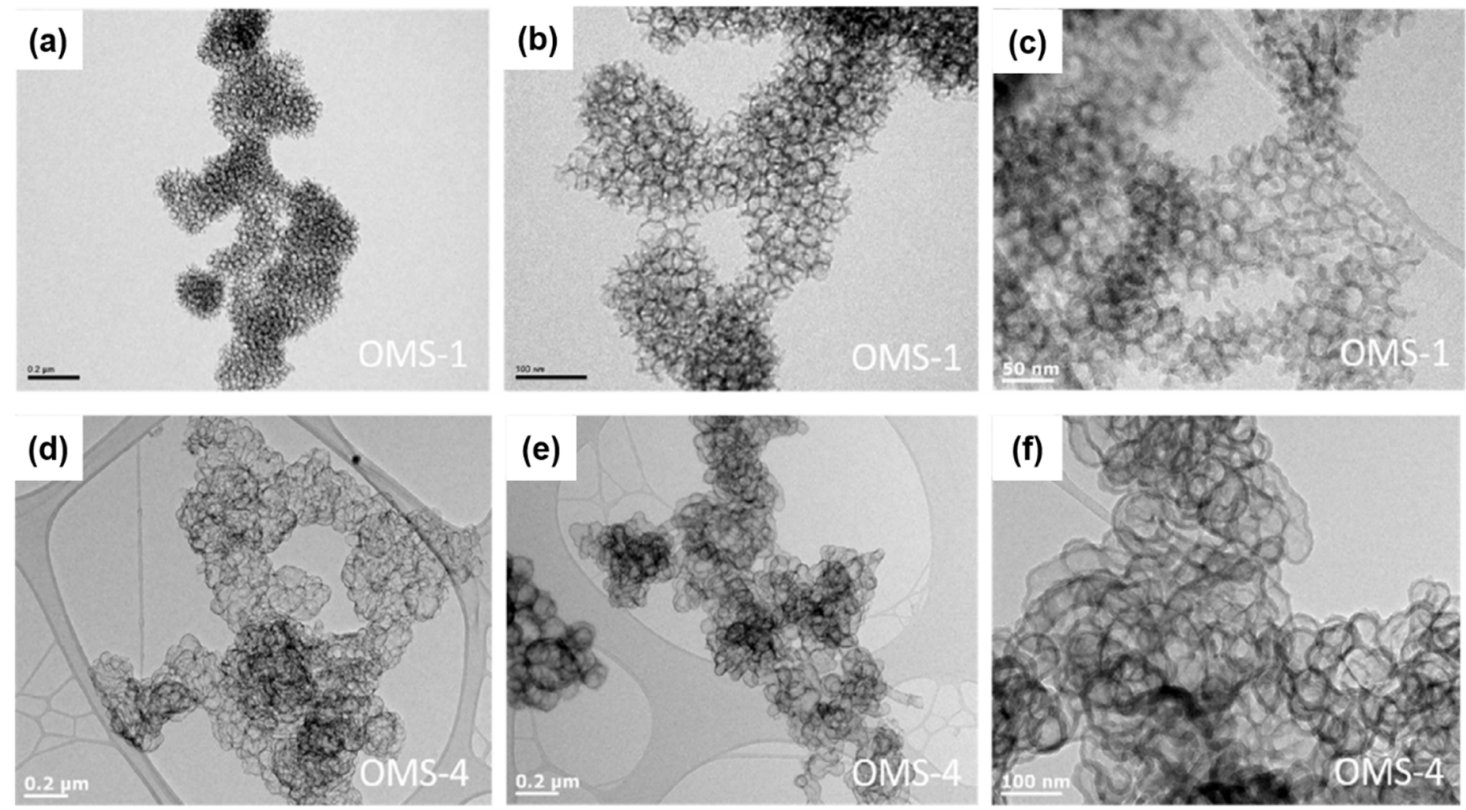

Figure 9. TEM images of large pore-sized ordered mesoporous silica made from rice husk-derived silicate: $(\mathbf{a}-\mathbf{c})$ mesocellular foam type with a pore size of $\sim 30 \mathrm{~nm}$ and $(\mathbf{d}-\mathbf{f})$ an expanded pore size of $\sim 60 \mathrm{~nm}$ (reprinted with permission from [103], Copyright 2020, Elsevier).

\section{Conclusions and Perspectives}

To date, we covered the purification of the silica component from rice husk and its use for the synthesis of engineered silica particles in previous studies. In particular, silica particles obtained by the bottom-up process using liquid silicate extracted from rice husk have been dealt with in detail. Morphologically controlled and ordered porous silica particles can be manufactured through various methods based on the bottom-up process. These engineered silica particles have unique properties including uniform shapes and sizes, large surface areas and pore volumes, and precisely controlled mesopores. Within the scope of this review, the following conclusions can be drawn:

- The widely used method for obtaining silica from rice husks is direct combustion. The characteristics of shape, particle size, pore, and uniformity can be controlled by changing the combustion conditions but its changes could be within a narrow range. Therefore, chemical treatment should be followed to synthesize the engineered silica particles.

- The main components of rice husk—cellulose, hemicellulose, lignin and inorganics—can be separated by their thermo-chemical properties.

- Acid leaching using a strong acid solution (e.g., $\mathrm{H}_{2} \mathrm{SO}_{4}, \mathrm{HCl}$, and $\mathrm{HNO}_{3}$ ) is effective to produce silica with high purity and surface area. However, these reagents are significantly hazardous to the environment and human life. Therefore, attempts to use environmentally harmless agents, such as citric acid and ionic liquid, have been reported.

- Silica can be extracted from rice husk by solubilizing it in an alkali solution and precipitating in an acidic medium. In general, sodium hydroxide was used to extract silica from rice husk as sodium silicate.

- The development of synthetic methods based on bottom-up processes enables the precise and uniform control of the morphological properties of silica products. These methods generally use a sodium silicate solution extracted from rice husks as a raw material.

- The neutralization of sodium silicate solution using acidic solution (e.g., $\mathrm{H}_{2} \mathrm{SO}_{4}, \mathrm{HCl}, \mathrm{HNO}_{3}$, organic acid) is a common method for the precipitation of silica particles. However, it is still not possible to accurately control the morphological properties of silica. 
- The use of (i) organic co-solvents (e.g., ethanol and acetone), (ii) polymer additives (e.g., PEG), and (iii) a water-in-oil emulsion system enables the control of the morphological properties, such as the shape and size, of silica particles.

- Various ordered porous silica particles including MCM-type, SBA-type, and mesocellular foam structure have been successfully obtained from a rice husk-derived silicate solution with additional structure directing agents (e.g., CTAB, Pluronic P-123, etc.).

Based on these properties, they are expected to be utilized in potential value-added applications, such as heterogeneous catalysts, $\mathrm{CO}_{2}$ capture, adsorbents for aqueous pollutants, biomolecular delivery, and cosmetic ingredients. The rice husk-derived engineered silica will further increase their value in modern society because they are manufactured from sustainable biomass resources.

For the practical use of engineered silica particles made from rice husks, several important issues must be addressed. As described in the previous chapter, the combustion of rice husks to remove organic components generates greenhouse gases and emits significant quantities of particulate matter. The use of strong acids to obtain high-purity silica is significantly hazardous to the environment and human life. Moreover, the overall synthesis procedure is complex, as shown in Figure 10a. As a result, the unit price of the final product is higher than those of silica particles made from mineral resources. We believe that overcoming these obstacles in the synthetic process is a prerequisite for the commercialization of engineered silica particles made from rice husks. One strategy for the preparation of rice husk-derived engineered silica through an environmentally friendly and cost-competitive process is proposed in Figure 10b. The direct extraction of silicate from rice husks using alkaline solution and thereafter titration using weak acids with polymer additives or co-solvents simplifies the overall process, while the use and emission of harmful substances can be minimized. However, the direct extraction of silicate using alkaline solution also leads to the extraction of organic components such as xylan. These organic components make it difficult to obtain engineered silica particles with high purity. Therefore, further research is needed to overcome these unresolved problems, and through this, it is expected that the commercialization of rice husk-derived silica will be one step closer.

(a)

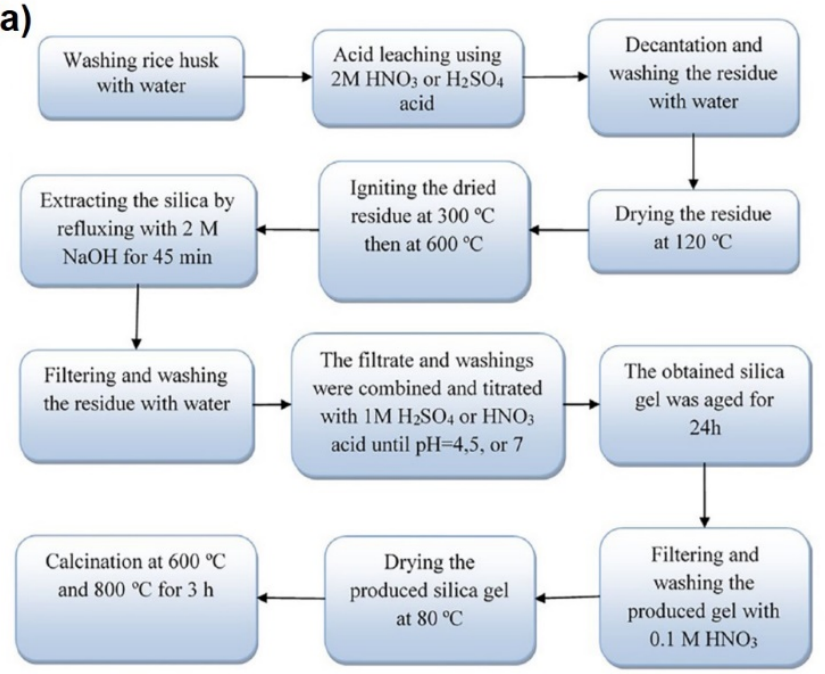

Figure 10. (a) General process (reprinted with permission from [62], Copyright 2019, Elsevier); and (b) the simplified and environmentally friendly process for the preparation of engineered silica particles from rice husk.

Author Contributions: Conceptualization, investigation and writing—original draft, project administration J.H.L.; investigation and writing - original draft, writing - review and editing, J.C. All authors have read and agreed to the published version of the manuscript. (b)

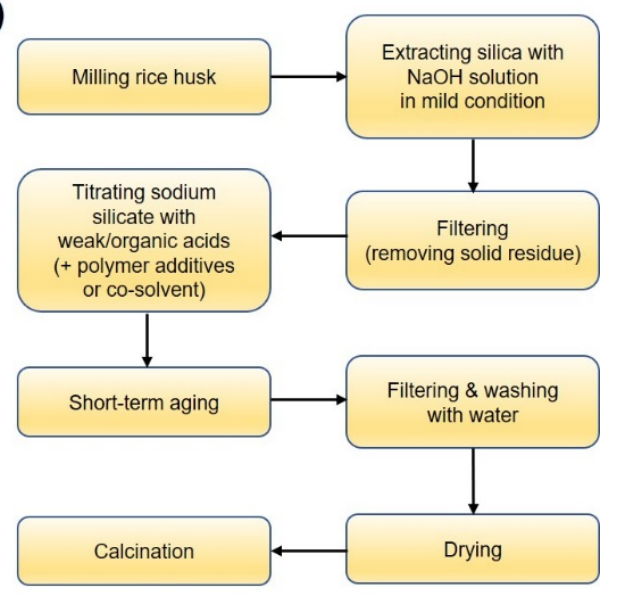


Funding: This research was supported by the R\&D program of Korea Institute of Energy Technology Evaluation and Planning (KETEP) grant funded by the Ministry of Trade, Industry and Energy (MOTIE), the Republic of Korea (No. 20183030091950).

Conflicts of Interest: The authors declare no conflict of interest.

\section{References}

1. FAOSTAT. Available online: http://www.fao.org/faostat/en/\#data/QC (accessed on 12 November 2020).

2. Bhattacharyya, S.C. Viability of off-grid electricity supply using rice husk: A case study from South Asia. Biomass Bioenergy 2014, 68, 44-54. [CrossRef]

3. Quispe, I.; Navia, R.; Kahhat, R. Energy potential from rice husk through direct combustion and fast pyrolysis: A review. Waste Manag. 2017, 59, 200-210. [CrossRef] [PubMed]

4. Asadullah, M. Barriers of commercial power generation using biomass gasification gas: A review. Renew. Sustain. Energy Rev. 2014, 29, 201-215. [CrossRef]

5. Hiloidhari, M.; Baruah, D. Crop residue biomass for decentralized electrical power generation in rural areas (part 1): Investigation of spatial availability. Renew. Sustain. Energy Rev. 2011, 15, 1885-1892. [CrossRef]

6. Assanee, N.; Boonwan, C. State of the art of biomass gasification power plants in Thailand. Energy Procedia 2011, 9, 299-305. [CrossRef]

7. Pode, R. Potential applications of rice husk ash waste from rice husk biomass power plant. Renew. Sustain. Energy Rev. 2016, 53, 1468-1485. [CrossRef]

8. Lin, Y.-S.; Hurley, K.R.; Haynes, C.L. Critical considerations in the biomedical use of mesoporous silica nanoparticles. J. Phys. Chem. Lett. 2012, 3, 364-374. [CrossRef]

9. Liu, B.; Li, C.; Cheng, Z.; Hou, Z.; Huang, S.; Lin, J. Functional nanomaterials for near-infrared-triggered cancer therapy. Biomater. Sci. 2016, 4, 890-909. [CrossRef]

10. Wang, Y.; Zhao, Q.; Han, N.; Bai, L.; Li, J.; Liu, J.; Che, E.; Hu, L.; Zhang, Q.; Jiang, T. Mesoporous silica nanoparticles in drug delivery and biomedical applications. Nanomedicine 2015, 11, 313-327. [CrossRef]

11. Jung, D.S.; Ryou, M.-H.; Sung, Y.J.; Park, S.B.; Choi, J.W. Recycling rice husks for high-capacity lithium battery anodes. Proc. Natl. Acad. Sci. USA 2013, 110, 12229-12234. [CrossRef]

12. Shen, Y. Rice husk silica-derived nanomaterials for battery applications: A literature review. J. Agric. Food Chem. 2017, 65, 995-1004. [CrossRef] [PubMed]

13. Kumari, B.; Singh, D. A review on multifaceted application of nanoparticles in the field of bioremediation of petroleum hydrocarbons. Ecol. Eng. 2016, 97, 98-105. [CrossRef]

14. Van Tuan, N.; Ye, G.; Van Breugel, K.; Copuroglu, O. Hydration and microstructure of ultra high performance concrete incorporating rice husk ash. Cem. Concr. Res. 2011, 41, 1104-1111. [CrossRef]

15. Martirena, F.; Monzó, J. Vegetable ashes as supplementary cementitious materials. Cem. Concr. Res. 2018, 114, 57-64. [CrossRef]

16. Kang, S.-H.; Hong, S.-G.; Moon, J. The use of rice husk ash as reactive filler in ultra-high performance concrete. Cem. Concr. Res. 2019, 115, 389-400. [CrossRef]

17. Kang, S.-H.; Kwon, Y.-H.; Hong, S.-G.; Chun, S.; Moon, J. Hydrated lime activation on byproducts for eco-friendly production of structural mortars. J. Clean Prod. 2019, 231, 1389-1398. [CrossRef]

18. Shen, Y. Rice husk silica derived nanomaterials for sustainable applications. Renew. Sustain. Energy Rev. 2017, 80, 453-466. [CrossRef]

19. Lee, J.H.; Kwon, J.H.; Lee, J.-W.; Lee, H.-s.; Chang, J.H.; Sang, B.-I. Preparation of high purity silica originated from rice husks by chemically removing metallic impurities. J. Ind. Eng. Chem. 2017, 50, 79-85. [CrossRef]

20. Fernandes, I.J.; Calheiro, D.; Kieling, A.G.; Moraes, C.A.; Rocha, T.L.; Brehm, F.A.; Modolo, R.C. Characterization of rice husk ash produced using different biomass combustion techniques for energy. Fuel 2016, 165, 351-359. [CrossRef]

21. Zulfiqar, U.; Subhani, T.; Husain, S.W. Towards tunable size of silica particles from rice husk. J. Non-Cryst. Solids 2015, 429, 61-69. [CrossRef]

22. Junpen, A.; Pansuk, J.; Kamnoet, O.; Cheewaphongphan, P.; Garivait, S. Emission of air pollutants from rice residue open burning in Thailand, 2018. Atmosphere 2018, 9, 449. [CrossRef] 
23. Lasko, K.; Vadrevu, K. Improved rice residue burning emissions estimates: Accounting for practice-specific emission factors in air pollution assessments of Vietnam. Environ. Pollut. 2018, 236, 795-806. [CrossRef] [PubMed]

24. Nakata, Y.; Suzuki, M.; Okutani, T.; Kikuchi, M.; Akiyama, T. Preparation and properties of $\mathrm{SiO}_{2}$ from rice hulls. J. Ceram. Soc. Jpn. 1989, 97, 842-849. [CrossRef]

25. Beidaghy Dizaji, H.; Zeng, T.; Hartmann, I.; Enke, D.; Schliermann, T.; Lenz, V.; Bidabadi, M. Generation of high quality biogenic silica by combustion of rice husk and rice straw combined with pre-and post-treatment strategies-A review. Appl. Sci. 2019, 9, 1083. [CrossRef]

26. Zareihassangheshlaghi, A.; Beidaghy Dizaji, H.; Zeng, T.; Huth, P.; Ruf, T.; Denecke, R.; Enke, D. Behavior of metal impurities on surface and bulk of biogenic silica from rice husk combustion and the impact on ash-melting tendency. ACS Sustain. Chem. Eng. 2020, 8, 10369-10379. [CrossRef]

27. Alyosef, H.A.; Eilert, A.; Welscher, J.; Ibrahim, S.S.; Denecke, R.; Schwieger, W.; Enke, D. Characterization of biogenic silica generated by thermo chemical treatment of rice husk. Part. Sci. Technol. 2013, 31, 524-532. [CrossRef]

28. Pedersen, M.; Meyer, A.S. Lignocellulose pretreatment severity-relating $\mathrm{pH}$ to biomatrix opening. New Biotechnol. 2010, 27, 739-750. [CrossRef]

29. Pedersen, M.; Viksø-Nielsen, A.; Meyer, A.S. Monosaccharide yields and lignin removal from wheat straw in response to catalyst type and $\mathrm{pH}$ during mild thermal pretreatment. Process Biochem. 2010, 45, 1181-1186. [CrossRef]

30. Kristensen, J.B.; Thygesen, L.G.; Felby, C.; Jørgensen, H.; Elder, T. Cell-wall structural changes in wheat straw pretreated for bioethanol production. Biotechnol. Biofuels 2008, 1, 5. [CrossRef]

31. Alexander, G.B.; Heston, W.; Iler, R.K. The solubility of amorphous silica in water. J. Phys. Chem. 1954, 58, 453-455. [CrossRef]

32. Real, C.; Alcala, M.D.; Criado, J.M. Preparation of silica from rice husks. J. Am. Ceram. Soc. 1996, 79, 2012-2016. [CrossRef]

33. Liou, T.-H.; Yang, C.-C. Synthesis and surface characteristics of nanosilica produced from alkali-extracted rice husk ash. Mater. Sci. Eng. B 2011, 176, 521-529. [CrossRef]

34. Chen, P.; Bie, H.; Bie, R. Leaching characteristics and kinetics of the metal impurities present in rice husk during pretreatment for the production of nanosilica particles. Korean J. Chem. Eng. 2018, 35, 1911-1918. [CrossRef]

35. Chakraverty, A.; Mishra, P.; Banerjee, H. Investigation of combustion of raw and acid-leached rice husk for production of pure amorphous white silica. J. Mater. Sci. 1988, 23, 21-24. [CrossRef]

36. Vayghan, A.G.; Khaloo, A.; Rajabipour, F. The effects of a hydrochloric acid pre-treatment on the physicochemical properties and pozzolanic performance of rice husk ash. Cem. Concr. Compos. 2013, 39, 131-140. [CrossRef]

37. Umeda, J.; Kondoh, K. High-purity amorphous silica originated in rice husks via carboxylic acid leaching process. J. Mater. Sci. 2008, 43, 7084-7090. [CrossRef]

38. Umeda, J.; Kondoh, K. Process optimization to prepare high-purity amorphous silica from rice husks via citric acid leaching treatment. Trans. JWRI 2008, 37, 13-17.

39. Chen, H.; Wang, W.; Martin, J.C.; Oliphant, A.J.; Doerr, P.A.; Xu, J.F.; DeBorn, K.M.; Chen, C.; Sun, L. Extraction of lignocellulose and synthesis of porous silica nanoparticles from rice husks: A comprehensive utilization of rice husk biomass. ACS Sustain. Chem. Eng. 2013, 1, 254-259. [CrossRef]

40. Shen, J.; Liu, X.; Zhu, S.; Zhang, H.; Tan, J. Effects of calcination parameters on the silica phase of original and leached rice husk ash. Mater. Lett. 2011, 65, 1179-1183. [CrossRef]

41. Trinh, L.T.P.; Lee, Y.J.; Lee, J.-W.; Lee, H.-J. Characterization of ionic liquid pretreatment and the bioconversion of pretreated mixed softwood biomass. Biomass Bioenergy 2015, 81, 1-8. [CrossRef]

42. Mochidzuki, K.; Sakoda, A.; Suzuki, M.; Izumi, J.; Tomonaga, N. Structural behavior of rice husk silica in pressurized hot-water treatment processes. Ind. Eng. Chem. Res. 2001, 40, 5705-5709. [CrossRef]

43. Ahmad Alyosef, H.; Schneider, D.; Wassersleben, S.; Roggendorf, H.; Weiß, M.; Eilert, A.; Denecke, R.; Hartmann, I.; Enke, D. Meso/macroporous silica from miscanthus, cereal remnant pellets, and wheat straw. ACS Sustain. Chem. Eng. 2015, 3, 2012-2021. [CrossRef]

44. Moroz, I.K.; Maslennikova, G. Thermal transformations of silica. Glass Ceram. 1985, 42, 559-564. [CrossRef] 
45. Kim, T.H.; Ryu, H.J.; Oh, K.K. Improvement of organosolv fractionation performance for rice husk through a low acid-catalyzation. Energies 2019, 12, 1800. [CrossRef]

46. Zhang, H.; Ding, X.; Chen, X.; Ma, Y.; Wang, Z.; Zhao, X. A new method of utilizing rice husk: Consecutively preparing d-xylose, organosolv lignin, ethanol and amorphous superfine silica. J. Hazard. Mater. 2015, 291, 65-73. [CrossRef]

47. Tchakouté, H.K.; Rüscher, C.H.; Kong, S.; Kamseu, E.; Leonelli, C. Geopolymer binders from metakaolin using sodium waterglass from waste glass and rice husk ash as alternative activators: A comparative study. Constr. Build. Mater. 2016, 114, 276-289. [CrossRef]

48. Geraldo, R.H.; Fernandes, L.F.; Camarini, G. Water treatment sludge and rice husk ash to sustainable geopolymer production. J. Clean. Prod. 2017, 149, 146-155. [CrossRef]

49. Tchakouté, H.K.; Rüscher, C.H.; Kong, S.; Ranjbar, N. Synthesis of sodium waterglass from white rice husk ash as an activator to produce metakaolin-based geopolymer cements. J. Build. Eng. 2016, 6, 252-261. [CrossRef]

50. Jahan, M.S.; Haris, F.; Rahman, M.M.; Samaddar, P.R.; Sutradhar, S. Potassium hydroxide pulping of rice straw in biorefinery initiatives. Bioresour. Technol. 2016, 219, 445-450. [CrossRef]

51. Bernal, S.A.; Rodríguez, E.D.; de Gutiérrez, R.M.; Provis, J.L.; Delvasto, S. Activation of metakaolin/slag blends using alkaline solutions based on chemically modified silica fume and rice husk ash. Waste Biomass Valoriz. 2012, 3, 99-108. [CrossRef]

52. Bernal, S.; Rodríguez, E.; Mejía de Gutiérrez, R.; Provis, J.L. Performance at high temperature of alkali-activated slag pastes produced with silica fume and rice husk ash based activators. Mater. Constr. 2015, 65, e049. [CrossRef]

53. Kamseu, E.; à Moungam, L.B.; Cannio, M.; Billong, N.; Chaysuwan, D.; Melo, U.C.; Leonelli, C. Substitution of sodium silicate with rice husk ash- $\mathrm{NaOH}$ solution in metakaolin based geopolymer cement concerning reduction in global warming. J. Clean. Prod. 2017, 142, 3050-3060. [CrossRef]

54. Mejía, J.; de Gutiérrez, R.M.; Puertas, F. Rice husk ash as a source of silica in alkali-activated fly ash and granulated blast furnace slag systems. Mater. Constr. 2013, 63, 361-375.

55. Mejía, J.M.; de Gutiérrez, R.M.; Montes, C. Rice husk ash and spent diatomaceous earth as a source of silica to fabricate a geopolymeric binary binder. J. Clean. Prod. 2016, 118, 133-139. [CrossRef]

56. Bazargan, A.; Wang, Z.; Barford, J.P.; Saleem, J.; McKay, G. Optimization of the removal of lignin and silica from rice husks with alkaline peroxide. J. Clean. Prod. 2020, 260, 120848. [CrossRef]

57. Soltani, N.; Bahrami, A.; Pech-Canul, M.; González, L. Review on the physicochemical treatments of rice husk for production of advanced materials. Chem. Eng. J. 2015, 264, 899-935. [CrossRef]

58. Muñoz-Aguado, M.-J.; Gregorkiewitz, M. Sol-gel synthesis of microporous amorphous silica from purely inorganic precursors. J. Colloid Interface Sci. 1997, 185, 459-465. [CrossRef]

59. Schlomach, J.; Kind, M. Investigations on the semi-batch precipitation of silica. J. Colloid Interface Sci. 2004, 277, 316-326. [CrossRef] [PubMed]

60. Ghorbani, F.; Sanati, A.M.; Maleki, M. Production of silica nanoparticles from rice husk as agricultural waste by environmental friendly technique. Environ. Stud. Persian Gulf 2015, 2, 56-65.

61. Kamath, S.R.; Proctor, A. Silica gel from rice hull ash: Preparation and characterization. Cereal Chem. 1998, 75, 484-487. [CrossRef]

62. Nassar, M.Y.; Ahmed, I.S.; Raya, M.A. A facile and tunable approach for synthesis of pure silica nanostructures from rice husk for the removal of ciprofloxacin drug from polluted aqueous solutions. J. Mol. Liq. 2019, 282, 251-263. [CrossRef]

63. Vaibhav, V.; Vijayalakshmi, U.; Roopan, S.M. Agricultural waste as a source for the production of silica nanoparticles. Spectrochim. Acta A Mol. Biomol. Spectrosc. 2015, 139, 515-520. [CrossRef]

64. Adam, F.; Chew, T.-S.; Andas, J. A simple template-free sol-gel synthesis of spherical nanosilica from agricultural biomass. J. Sol-Gel Sci. Technol. 2011, 59, 580-583. [CrossRef]

65. Davarpanah, J.; Sayahi, M.H.; Ghahremani, M.; Karkhoei, S. Synthesis and characterization of nano acid catalyst derived from rice husk silica and its application for the synthesis of 3, 4-dihydropyrimidinones/thiones compounds. J. Mol. Struct. 2019, 1181, 546-555. [CrossRef]

66. Song, S.; Cho, H.-B.; Kim, H.T. Surfactant-free synthesis of high surface area silica nanoparticles derived from rice husks by employing the Taguchi approach. J. Ind. Eng. Chem. 2018, 61, 281-287. [CrossRef] 
67. Azat, S.; Korobeinyk, A.; Moustakas, K.; Inglezakis, V. Sustainable production of pure silica from rice husk waste in Kazakhstan. J. Clean. Prod. 2019, 217, 352-359. [CrossRef]

68. Nayak, P.; Datta, A. Synthesis of $\mathrm{SiO}_{2}$-nanoparticles from rice husk ash and its comparison with commercial amorphous silica through material characterization. Silicon 2020. [CrossRef]

69. Ngoc, T.M.; Man, T.M.; Phong, M.T.; Nam, H.M.; Hieu, N.H. Fabrication of tubular ceramic-supported malic acid cross-linked poly (vinyl alcohol)/rice husk ash-silica nanocomposite membranes for ethanol dehydration by pervaporation. Korean J. Chem. Eng. 2019, 36, 584-590. [CrossRef]

70. Kalapathy, U.; Proctor, A.; Shultz, J. An improved method for production of silica from rice hull ash. Bioresour. Technol. 2002, 85, 285-289. [CrossRef]

71. Zulkifli, N.S.C.; Ab Rahman, I.; Mohamad, D.; Husein, A. A green sol-gel route for the synthesis of structurally controlled silica particles from rice husk for dental composite filler. Ceram. Int. 2013, 39, 4559-4567. [CrossRef]

72. Jung, C.Y.; Kim, J.S.; Chang, T.S.; Kim, S.T.; Lim, H.J.; Koo, S.M. One-step synthesis of structurally controlled silicate particles from sodium silicates using a simple precipitation process. Langmuir 2010, 26, 5456-5461. [CrossRef] [PubMed]

73. Rajan, R.; Zakaria, Y.; Shamsuddin, S.; Hassan, N.F.N. Robust synthesis of mono-dispersed spherical silica nanoparticle from rice husk for high definition latent fingermark development. Arab. J. Chem. 2020, 13, 8119-8132. [CrossRef]

74. Li, D.; Chen, D.; Zhu, X. Reduction in time required for synthesis of high specific surface area silica from pyrolyzed rice husk by precipitation at low pH. Bioresour. Technol. 2011, 102, 7001-7003. [CrossRef] [PubMed]

75. Li, D.; Zhu, X. Short-period synthesis of high specific surface area silica from rice husk char. Mater. Lett. 2011, 65, 1528-1530. [CrossRef]

76. Thuc, C.N.H.; Thuc, H.H. Synthesis of silica nanoparticles from Vietnamese rice husk by sol-gel method. Nanoscale Res. Lett. 2013, 8, 1-10.

77. Shahnani, M.; Mohebbi, M.; Mehdi, A.; Ghassempour, A.; Aboul-Enein, H.Y. Silica microspheres from rice husk: A good opportunity for chromatography stationary phase. Ind. Crop. Prod. 2018, 121, 236-240. [CrossRef]

78. Hwang, J.; Lee, J.H.; Chun, J. Facile approach for the synthesis of spherical mesoporous silica nanoparticles from sodium silicate. Mater. Lett. 2021, 283, 128765. [CrossRef]

79. Hasan, R.; Chong, C.; Bukhari, S.; Jusoh, R.; Setiabudi, H. Effective removal of Pb (II) by low-cost fibrous silica KCC-1 synthesized from silica-rich rice husk ash. J. Ind. Eng. Chem. 2019, 75, 262-270. [CrossRef]

80. Kresge, C.; Leonowicz, M.; Roth, W.J.; Vartuli, J.; Beck, J. Ordered mesoporous molecular sieves synthesized by a liquid-crystal template mechanism. Nature 1992, 359, 710-712. [CrossRef]

81. Ramalingam, R.J.; Appaturi, J.N.; Pulingam, T.; Al-Lohedan, H.A.; Al-dhayan, D.M. In-situ incorporation of ruthenium/copper nanoparticles in mesoporous silica derived from rice husk ash for catalytic acetylation of glycerol. Renew. Energy 2020, 160, 564-574. [CrossRef]

82. Jang, H.T.; Park, Y.; Ko, Y.S.; Lee, J.Y.; Margandan, B. Highly siliceous MCM-48 from rice husk ash for $\mathrm{CO}_{2}$ adsorption. Int. J. Greenh. Gas Control 2009, 3, 545-549. [CrossRef]

83. Bhagiyalakshmi, M.; Yun, L.J.; Anuradha, R.; Jang, H.T. Utilization of rice husk ash as silica source for the synthesis of mesoporous silicas and their application to $\mathrm{CO} 2$ adsorption through TREN/TEPA grafting. J. Hazard. Mater. 2010, 175, 928-938. [CrossRef] [PubMed]

84. Bhagiyalakshmi, M.; Yun, L.J.; Anuradha, R.; Jang, H.T. Synthesis of chloropropylamine grafted mesoporous MCM-41, MCM-48 and SBA-15 from rice husk ash: Their application to $\mathrm{CO}_{2}$ chemisorption. J. Porous Mater. 2010, 17, 475-484. [CrossRef]

85. Ahmad-Alyosef, H.; Uhlig, H.; Münster, T.; Kloess, G.; Einicke, W.; Gläser, R.; Enke, D. Biogenic silica from rice husk ash-Sustainable sources for the synthesis of value added silica. Chem. Eng. Trans. 2014, 37, 667-672.

86. Chiarakorn, S.; Areerob, T.; Grisdanurak, N. Influence of functional silanes on hydrophobicity of MCM-41 synthesized from rice husk. Sci. Technol. Adv. Mater. 2007, 8, 110-115. [CrossRef]

87. Artkla, S.; Kim, W.; Choi, W.; Wittayakun, J. Highly enhanced photocatalytic degradation of tetramethylammonium on the hybrid catalyst of titania and MCM-41 obtained from rice husk silica. Appl. Catal. B 2009, 91, 157-164. [CrossRef]

88. Suyanta, S.; Kuncaka, A. Utilization of rice husk as raw material in synthesis of mesoporous silicates MCM-41. Indones. J. Chem. 2011, 11, 279-284. [CrossRef] 
89. Appaturi, J.N.; Adam, F. A facile and efficient synthesis of styrene carbonate via cycloaddition of $\mathrm{CO}_{2}$ to styrene oxide over ordered mesoporous MCM-41-Imi/Br catalyst. Appl. Catal. B 2013, 136, 150-159. [CrossRef]

90. Renuka, N.; Praveen, A.; Anas, K. Influence of CTAB molar ratio in tuning the texture of rice husk silica into MCM 41 and SBA-16. Mater. Lett. 2013, 109, 70-73. [CrossRef]

91. Areerob, T.; Grisdanurak, N.; Chiarakorn, S. Utilization of rice husk silica as adsorbent for BTEX passive air sampler under high humidity condition. Environ. Sci. Pollut. Res. 2016, 23, 5538-5548. [CrossRef]

92. Nguyen, N.T.; Chen, S.-S.; Nguyen, N.C.; Nguyen, H.T.; Tsai, H.H.; Chang, C.T. Adsorption of methyl blue on mesoporous materials using rice husk ash as silica source. J. Nanosci. Nanotechnol. 2016, 16, 4108-4114. [CrossRef] [PubMed]

93. Costa, J.A.S.; Sarmento, V.H.; Romão, L.P.; Paranhos, C.M. Adsorption of organic compounds on mesoporous material from rice husk ash (RHA). Biomass Convers. Biorefin. 2020, 10, 1105-1120. [CrossRef]

94. Purnawira, B.; Purwaningsih, H.; Ervianto, Y.; Pratiwi, V.; Susanti, D.; Rochiem, R.; Purniawan, A. Synthesis and characterization of mesoporous silica nanoparticles (MSNp) MCM 41 from natural waste rice husk. IOP Conf. Ser. Mater. Sci. Eng. 2019, 541, 012018. [CrossRef]

95. Kamari, S.; Ghorbani, F. Extraction of highly pure silica from rice husk as an agricultural by-product and its application in the production of magnetic mesoporous silica MCM-41. Biomass Convers. Biorefin. 2020. [CrossRef]

96. Zhao, D.; Feng, J.; Huo, Q.; Melosh, N.; Fredrickson, G.H.; Chmelka, B.F.; Stucky, G.D. Triblock copolymer syntheses of mesoporous silica with periodic 50 to 300 angstrom pores. Science 1998, 279, 548-552. [CrossRef] [PubMed]

97. Chaudhary, V.; Sharma, S. An overview of ordered mesoporous material SBA-15: Synthesis, functionalization and application in oxidation reactions. J. Porous Mater. 2017, 24, 741-749. [CrossRef]

98. Henao, W.; Jaramillo, L.; López, D.; Romero-Sáez, M.; Buitrago-Sierra, R. Insights into the $\mathrm{CO}_{2}$ capture over amine-functionalized mesoporous silica adsorbents derived from rice husk ash. J. Environ. Chem. Eng. 2020, 8, 104362. [CrossRef]

99. Chareonpanich, M.; Nanta-Ngern, A.; Limtrakul, J. Short-period synthesis of ordered mesoporous silica SBA-15 using ultrasonic technique. Mater. Lett. 2007, 61, 5153-5156. [CrossRef]

100. Ho, S.T.; Dinh, Q.K.; Tran, T.H.; Nguyen, H.P.; Nguyen, T.D. One-step synthesis of ordered Sn-substituted SBA-16 mesoporous materials using prepared silica source of rice husk and their selectively catalytic activity. Can. J. Chem. Eng. 2013, 91, 34-46. [CrossRef]

101. Bhagiyalakshmi, M.; Do Park, S.; Cha, W.S.; Jang, H.T. Development of TREN dendrimers over mesoporous SBA-15 for $\mathrm{CO}_{2}$ adsorption. Appl. Surf. Sci. 2010, 256, 6660-6666. [CrossRef]

102. Pimprom, S.; Sriboonkham, K.; Dittanet, P.; Föttinger, K.; Rupprechter, G.; Kongkachuichay, P. Synthesis of copper-nickel/SBA-15 from rice husk ash catalyst for dimethyl carbonate production from methanol and carbon dioxide. J. Ind. Eng. Chem. 2015, 31, 156-166. [CrossRef]

103. Chun, J.; Gu, Y.M.; Hwang, J.; Oh, K.K.; Lee, J.H. Synthesis of ordered mesoporous silica with various pore structures using high-purity silica extracted from rice husk. J. Ind. Eng. Chem. 2020, 81, 135-143. [CrossRef]

104. Kim, S.-S.; Pauly, T.R.; Pinnavaia, T.J. Non-ionic surfactant assembly of ordered, very large pore molecular sieve silicas from water soluble silicates. Chem. Commun. 2000, 1661-1662. [CrossRef]

105. Boissière, C.; Martines, M.A.; Tokumoto, M.; Larbot, A.; Prouzet, E. Mechanisms of pore size control in MSU-X mesoporous silica. Chem. Mater. 2003, 15, 509-515. [CrossRef]

106. Wajima, T.; Kiguchi, O.; Sugawara, K.; Sugawara, T. Synthesis of zeolite-A using silica from rice husk ash. J. Chem. Eng. Jpn. 2009, 42, s61-s66. [CrossRef]

107. Wittayakun, J.; Khemthong, P.; Prayoonpokarach, S. Synthesis and characterization of zeolite NaY from rice husk silica. Korean J. Chem. Eng. 2008, 25, 861-864. [CrossRef]

108. Mohamed, R.; Mkhalid, I.; Barakat, M. Rice husk ash as a renewable source for the production of zeolite NaY and its characterization. Arab. J. Chem. 2015, 8, 48-53. [CrossRef]

109. Vempati, R.K.; Borade, R.; Hegde, R.S.; Komarneni, S. Template free ZSM-5 from siliceous rice hull ash with varying C contents. Microporous Mesoporous Mater. 2006, 93, 134-140. [CrossRef]

110. Loiha, S.; Prayoonpokarach, S.; Songsiriritthigun, P.; Wittayakun, J. Synthesis of zeolite beta with pretreated rice husk silica and its transformation to ZSM-12. Mater. Chem. Phys. 2009, 115, 637-640. [CrossRef] 
111. Wang, H.P.; Lin, K.S.; Huang, Y.; Li, M.; Tsaur, L. Synthesis of zeolite ZSM-48 from rice husk ash. J. Hazard. Mater. 1998, 58, 147-152. [CrossRef]

112. Ng, E.-P.; Lim, G.K.; Khoo, G.-L.; Tan, K.-H.; Ooi, B.S.; Adam, F.; Ling, T.C.; Wong, K.-L. Synthesis of colloidal stable Linde Type J (LTJ) zeolite nanocrystals from rice husk silica and their catalytic performance in Knoevenagel reaction. Mater. Chem. Phys. 2015, 155, 30-35. [CrossRef]

113. Shen, Y.; Zhao, P.; Shao, Q. Porous silica and carbon derived materials from rice husk pyrolysis char. Microporous Mesoporous Mater. 2014, 188, 46-76. [CrossRef]

Publisher's Note: MDPI stays neutral with regard to jurisdictional claims in published maps and institutional affiliations.

(C) 2020 by the authors. Licensee MDPI, Basel, Switzerland. This article is an open access article distributed under the terms and conditions of the Creative Commons Attribution (CC BY) license (http://creativecommons.org/licenses/by/4.0/). 